\title{
A Survey on Data Mining
}

\author{
Balamurugan.V \\ PG Scholar, Department of Computer Science and Engineering, \\ Angel College of Engineering and Technology, Tirupur, TN, India
}

\begin{abstract}
Data mining helps end users extract useful business information from large databases. Data mining is used to build a predictive model. Data Mining is used to find the hidden information form the large databases. Data Mining is also called as knowledge Discovery. It is the process of analyzing data from different perspectives and summarizing it into useful information. Data mining has not only applied effectively in business environment but also in other fields such as weather forecast, medicine, transportation, healthcare, insurance, government and etc., data mining also has its own disadvantages as well such as privacy, security and misuse of information. We will examine the advantage and disadvantages of data mining in different industries.
\end{abstract}

Keywords-mining, mining methods and algorithms.

\section{Introduction}

Data mining, the extraction of hidden predictive information from large databases, is a powerful new technology with great potential to help companies focus on the most important information in their data warehouses. Data mining tools predict future trends and behaviors, allowing businesses to make proactive, knowledge-driven decisions. The automated, prospective analyses offered by data mining move beyond the analyses of past events provided by retrospective tools typical of decision support systems. Data mining tools can answer business questions that traditionally were too time consuming to resolve. They scour databases for hidden patterns, finding predictive information that experts may miss because it lies outside their expectations. Most companies already collect and refine massive quantities of data. Data mining techniques can be implemented rapidly on existing software and hardware platforms to enhance the value of existing information resources, and can be integrated with new products and systems as they are brought on-line. When implemented on high performance client/server or parallel processing computers, data mining tools can analyze massive databases to deliver answers to questions such as, "Which clients are most likely to respond to my next promotional mailing, and why?"

This white paper provides an introduction to the basic technologies of data mining. Examples of profitable applications illustrate its relevance to today's business environment as well as a basic description of how data warehouse architectures can evolve to deliver the value of data mining to end users.

\subsection{FOUNDATIONS OF DATA MINING}

Data mining techniques are the result of a long process of research and product development. This evolution began when business data was first stored on computers, continued with improvements in data access, and more recently, generated technologies that allow users to navigate through their data in real time. Data mining takes this evolutionary process beyond retrospective data access and navigation to prospective and proactive information delivery. Data mining is ready for application in the business community because it is supported by three technologies that are now sufficiently mature:

- Massive data collection.

- Powerful multiprocessor computers.

- Data mining algorithms.

\begin{tabular}{|c|c|c|c|c|}
\hline $\begin{array}{l}\text { Evolutionary } \\
\text { Step }\end{array}$ & Business Question & $\begin{array}{l}\text { Enabling } \\
\text { Technologies }\end{array}$ & $\begin{array}{l}\text { Product } \\
\text { Providers }\end{array}$ & Characteristics \\
\hline $\begin{array}{l}\text { Data Collection } \\
(1960 \mathrm{~s})\end{array}$ & $\begin{array}{l}\text { "What was my total } \\
\text { revenue in the last five } \\
\text { years?" }\end{array}$ & $\begin{array}{l}\text { Computers, tapes, } \\
\text { disks }\end{array}$ & $\mathrm{IBM}, \mathrm{CDC}$ & $\begin{array}{l}\text { Retrospective, } \\
\text { static data } \\
\text { delivery }\end{array}$ \\
\hline $\begin{array}{l}\text { Data Access } \\
(1980 \mathrm{~s})\end{array}$ & $\begin{array}{l}\text { "What were unit sales in } \\
\text { New England last }\end{array}$ & $\begin{array}{l}\text { Relational databases } \\
\text { (RDBMS), Structured }\end{array}$ & $\begin{array}{l}\text { Oracle, Sybase, } \\
\text { Informix, IBM, }\end{array}$ & $\begin{array}{l}\text { Retrospective, } \\
\text { dynamic data }\end{array}$ \\
\hline
\end{tabular}




\begin{tabular}{|c|c|c|c|c|}
\hline & March?" & $\begin{array}{l}\text { Query Language } \\
\text { (SQL), ODBC }\end{array}$ & Microsoft & $\begin{array}{l}\text { delivery at } \\
\text { record level }\end{array}$ \\
\hline $\begin{array}{l}\text { Data } \\
\text { Warehousing \& } \\
\text { Decision Support } \\
\text { (1990s) }\end{array}$ & $\begin{array}{l}\text { "What were unit sales in } \\
\text { New England last March? } \\
\text { Drill down to Boston." }\end{array}$ & $\begin{array}{l}\text { On-line analytic } \\
\text { processing (OLAP), } \\
\text { multidimensional } \\
\text { databases, data } \\
\text { warehouses }\end{array}$ & $\begin{array}{l}\text { Pilot, } \\
\text { Comshare, } \\
\text { Arbor, Cognos, } \\
\text { Microstrategy }\end{array}$ & $\begin{array}{l}\text { Retrospective, } \\
\text { dynamic data } \\
\text { delivery at } \\
\text { multiple levels }\end{array}$ \\
\hline $\begin{array}{l}\text { Data Mining } \\
\text { (Emerging Today) }\end{array}$ & $\begin{array}{l}\text { "What's likely to happen } \\
\text { to Boston unit sales next } \\
\text { month? Why?" }\end{array}$ & $\begin{array}{l}\text { Advanced algorithms, } \\
\text { multiprocessor } \\
\text { computers, massive } \\
\text { databases }\end{array}$ & $\begin{array}{l}\text { Pilot, } \\
\text { Lockheed, } \\
\text { IBM, SGI, } \\
\text { numerous } \\
\text { startups } \\
\text { (nascent } \\
\text { industry) }\end{array}$ & $\begin{array}{l}\text { Prospective, } \\
\text { proactive } \\
\text { information } \\
\text { delivery }\end{array}$ \\
\hline
\end{tabular}

Table 1. Steps in the Evolution of Data Mining.

The core components of data mining technology have been under development for decades, in research areas such as statistics, artificial intelligence, and machine learning. Today, the maturity of these techniques, coupled with high-performance relational database engines and broad data integration efforts, make these technologies practical for current data warehouse environments.

\section{The Scope Of Data Mining}

Data mining derives its name from the similarities between searching for valuable business information in a large database for example, finding linked products in gigabytes of store scanner data and mining a mountain for a vein of valuable ore. Both processes require either sifting through an immense amount of material, or intelligently probing it to find exactly where the value resides. Given databases of sufficient size and quality, data mining technology can generate new business opportunities by providing these capabilities:

- Automated prediction of trends and behaviors. Data mining automates the process of finding predictive information in large databases. Questions that traditionally required extensive hands-on analysis can now be answered directly from the data quickly. A typical example of a predictive problem is targeted marketing. Data mining uses data on past promotional mailings to identify the targets most likely to maximize return on investment in future mailings. Other predictive problems include forecasting bankruptcy and other forms of default, and identifying segments of a population likely to respond similarly to given events.

- Automated discovery of previously unknown patterns. Data mining tools sweep through databases and identify previously hidden patterns in one step. An example of pattern discovery is the analysis of retail sales data to identify seemingly unrelated products that are often purchased together. Other pattern discovery problems include detecting fraudulent credit card transactions and identifying anomalous data that could represent data entry keying errors.

Data mining techniques can yield the benefits of automation on existing software and hardware platforms, and can be implemented on new systems as existing platforms are upgraded and new products developed. When data mining tools are implemented on high performance parallel processing systems, they can analyze massive databases in minutes. Faster processing means that users can automatically experiment with more models to understand complex data. High speed makes it practical for users to analyze huge quantities of data. Larger databases, in turn, yield improved predictions.

\section{Commonly Used Data Mining Techniques}

The most commonly used techniques in data mining are:

- Artificial neural networks: Non-linear predictive models that learn through training and resemble biological neural networks in structure.

- Decision trees: Tree-shaped structures that represent sets of decisions. These decisions generate rules for the classification of a dataset. Specific decision tree methods include Classification and Regression Trees (CART) and Chi Square Automatic Interaction Detection (CHAID) .

- Genetic algorithms: Optimization techniques that use processes such as genetic combination, mutation, and natural selection in a design based on the concepts of evolution. 
- Nearest neighbor method: A technique that classifies each record in a dataset based on a combination of the classes of the $\mathrm{k}$ record(s) most similar to it in a historical dataset (where $\mathrm{k}^{3} 1$ ). Sometimes called the k-nearest neighbor technique.

- Rule induction: The extraction of useful if-then rules from data based on statistical significance.

Many of these technologies have been in use for more than a decade in specialized analysis tools that work with relatively small volumes of data. These capabilities are now evolving to integrate directly with industry standard data warehouse and OLAP platforms. The appendix to this white paper provides a glossary of data mining terms.

\section{Data Mining Architecture}

To best apply these advanced techniques, they must be fully integrated with a data warehouse as well as flexible interactive business analysis tools. Many data mining tools currently operate outside of the warehouse, requiring extra steps for extracting, importing, and analyzing the data. Furthermore, when new insights require operational implementation, integration with the warehouse simplifies the application of results from data mining. The resulting analytic data warehouse can be applied to improve business processes throughout the organization, in areas such as promotional campaign management, fraud detection, new product rollout, and so on. Fig. 1 illustrates an architecture for advanced analysis in a large datawarehouse.

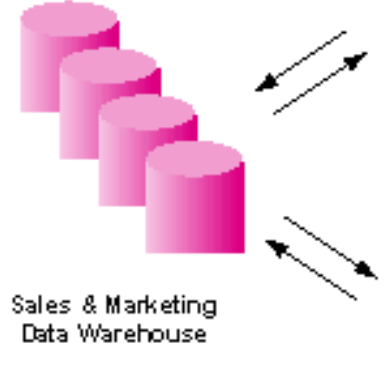

Figure 1 - Integrated Data Mining Architecture
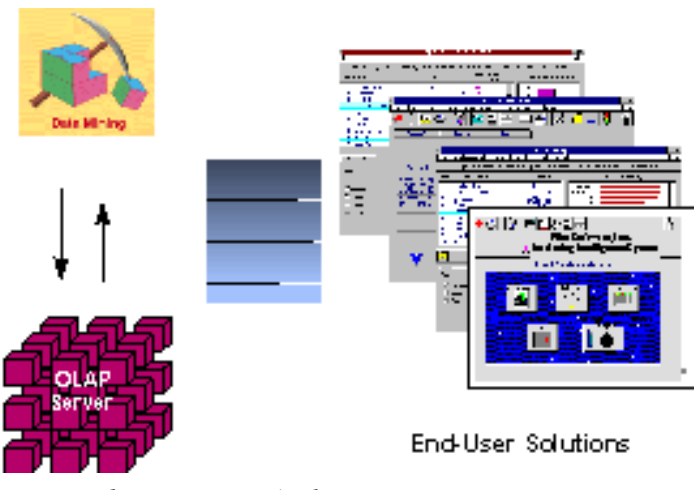

End-User Solutione

The ideal starting point is a data warehouse containing a combination of internal data tracking all customer contact coupled with external market data about competitor activity. Background information on potential customers also provides an excellent basis for prospecting. This warehouse can be implemented in a variety of relational database systems: Sybase, Oracle, Redbrick, and so on, and should be optimized for flexible and fast data access.

An OLAP (On-Line Analytical Processing) server enables a more sophisticated end-user business model to be applied when navigating the data warehouse. The multidimensional structures allow the user to analyze the data as they want to view their business - summarizing by product line, region, and other key perspectives of their business. The Data Mining Server must be integrated with the data warehouse and the OLAP server to embed ROI-focused business analysis directly into this infrastructure. An advanced, process-centric metadata template defines the data mining objectives for specific business issues like campaign management, prospecting, and promotion optimization. Integration with the data warehouse enables operational decisions to be directly implemented and tracked. As the warehouse grows with new decisions and results, the organization can continually mine the best practices and apply them to future decisions.

This design represents a fundamental shift from conventional decision support systems. Rather than simply delivering data to the end user through query and reporting software, the Advanced Analysis Server applies users' business models directly to the warehouse and returns a proactive analysis of the most relevant information. These results enhance the metadata in the OLAP Server by providing a dynamic metadata layer that represents a distilled view of the data. Reporting, visualization, and other analysis tools can then be applied to plan future actions and confirm the impact of those plans.

\section{Profitable Applications}

A wide range of companies have deployed successful applications of data mining. While early adopters of this technology have tended to be in information-intensive industries such as financial services and direct mail marketing, the technology is applicable to any company looking to leverage a large data warehouse to better manage their customer relationships. Two critical factors for success with data mining are: a large, wellintegrated data warehouse and a well-defined understanding of the business process within which data mining is to be applied (such as customer prospecting, retention, campaign management, and so on). 
Some successful application areas include:

- A pharmaceutical company can analyze its recent sales force activity and their results to improve targeting of high-value physicians and determine which marketing activities will have the greatest impact in the next few months. The data needs to include competitor market activity as well as information about the local health care systems. The results can be distributed to the sales force via a wide-area network that enables the representatives to review the recommendations from the perspective of the key attributes in the decision process. The ongoing, dynamic analysis of the data warehouse allows best practices from throughout the organization to be applied in specific sales situations.

- A credit card company can leverage its vast warehouse of customer transaction data to identify customers most likely to be interested in a new credit product. Using a small test mailing, the attributes of customers with an affinity for the product can be identified. Recent projects have indicated more than a 20 -fold decrease in costs for targeted mailing campaigns over conventional approaches.

- A diversified transportation company with a large direct sales force can apply data mining to identify the best prospects for its services. Using data mining to analyze its own customer experience, this company can build a unique segmentation identifying the attributes of high-value prospects. Applying this segmentation to a general business database such as those provided by Dun \& Bradstreet can yield a prioritized list of prospects by region.

- A large consumer package goods company can apply data mining to improve its sales process to retailers. Data from consumer panels, shipments, and competitor activity can be applied to understand the reasons for brand and store switching. Through this analysis, the manufacturer can select promotional strategies that best reach their target customer segments.

Each of these examples have a clear common ground. They leverage the knowledge about customers implicit in a data warehouse to reduce costs and improve the value of customer relationships. These organizations can now focus their efforts on the most important (profitable) customers and prospects, and design targeted marketing strategies to best reach them.

\section{Conclusion}

Since data mining is a young discipline with wide and diverse applications, there is still a nontrivial gap between general principles of data mining and domain specific, effective data mining tools for particular applications. A few application domains of Data Mining (such as finance, the retail industry and telecommunication) and Trends in Data Mining which include further efforts towards the exploration of new application areas and new methods for handling complex data types, algorithms scalability, constraint based mining and visualization methods, the integration of data mining with data warehousing and database systems, the standardization of data mining languages, and data privacy protection and security.

\section{References}

[1] Data Mining Concepts and Techniques - Jiawei Han \& Micheline Kamber

[2] Modern Data Warehousing, Mining and Visualization Core Concepts by George

[3] http://www.thearling.com/text/dmwhite/dmwhite.htm

[4] http://www.rimtengg.com/coit2007/proceedings/pdfs/94.pdf

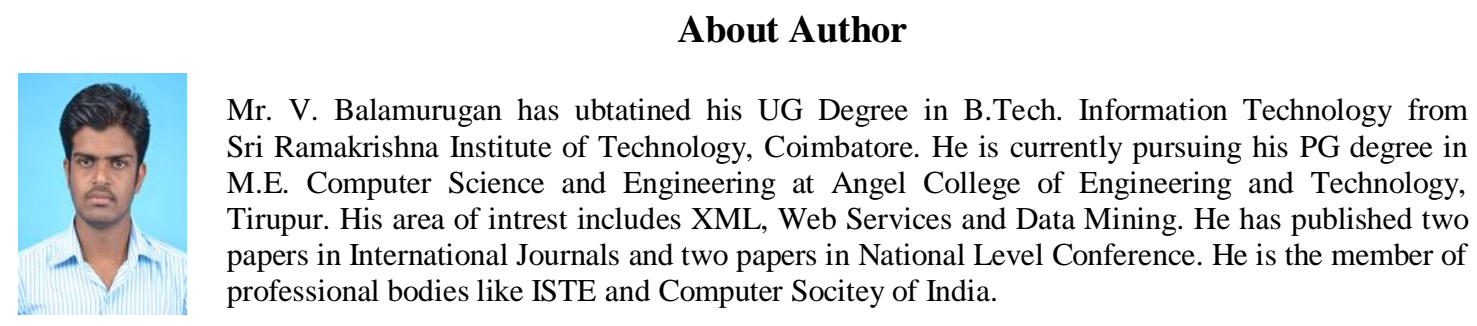

